\title{
Agreeing on generalised Darwinism: a response to Pavel Pelikan
}

\author{
Geoffrey Martin Hodgson • Thorbjoern Knudsen
}

Published online: 5 November 2011

(C) Springer-Verlag 2011

\begin{abstract}
Pelikan (J Evol Econ 21:341-366, 2011) develops an interesting conceptual framework that adds to prior work on generalised Darwinism. Despite claims to the contrary we show that it is similar to the approach developed by Hodgson and Knudsen (J Evol Econ 16(4):343-366, 2006a, J Econ Behav Organ 75(1):12-24, 2010a, b), Aldrich et al. (J Evol Econ 18(5):577-596, 2008) and others. Pelikan also mischaracterises the Hodgson-Knudsen position over Lamarckism. We show why the term is misleading (rather than strictly wrong) when applied to social evolution.
\end{abstract}

Keywords Generalised Darwinism • Lamarckism • Replication

JEL Classification B52

We find much agreement with the interesting article by Pavel Pelikan (2011), where he develops a version of generalised Darwinism and shows its relevance for the social sciences. In many ways this is similar to the position that we have developed elsewhere (Hodgson and Knudsen 2006a, 2010b, Aldrich et al.

G. M. Hodgson ( $\varangle)$

The Business School, University of Hertfordshire,

De Havilland Campus, Hatfield, Hertfordshire AL10 9AB, UK

e-mail: g.m.hodgson@herts.ac.uk

T. Knudsen

Strategic Organization Design Unit, Danish Institute for Advanced Study,

University of Southern Denmark, 5230 Odense M, Denmark 
2008). But to our surprise, we find our colleague picking quarrels where none exist. $^{1}$

There are differences in chosen terminology, but these can be negotiated if each scholar examines carefully the meanings given to each term. There are also some mischaracterisations of our position, including on the question of Lamarckism. Part of the problem here is Pelikan's imprecise use of several concepts, including controversial ones such as 'methodological individualism' and 'Lamarckism'.

In sequence this response outlines the common ground, shows that several points of alleged opposition do not exist and deals as concisely as possible with the tricky question of Lamarckism.

\section{Our common ground}

Pelikan is one of a growing number of social scientists who are working on the generalisation of Darwinian principles to social evolution. He has made a significant contribution. One of the positive and useful features of Pelikan's article is his argument that 'development is an inseparable but distinct companion of evolution' (p. 3). We agree entirely. In our work we have likewise raised the famous 'evo-devo' dispute and affirmed that 'development and selection are ... essential features of evolution' (Hodgson and Knudsen 2010b, p. 114). There seems to be no disagreement here.

Another common feature is our shared emphasis on the crucial role of information and instructions. Pelikan (2011, p. 343) writes: 'Evolution produces instructions for guiding development' and 'all uses of instructions require preexisting instructions.'

One of us used the 'instruction' language in a much earlier book, writing of 'information [that] consists of coded instructions programming or directing behaviour or growth' (Hodgson 1993, ch. 11). In Hodgson and Knudsen (2010b, pp. 65-66, 70-4, 77-8, 80, 84, 113, 117, 121-123, 132, 159-60, 226, 238, 241) we write of instructions in a similar sense. But we also use the replicator

\footnotetext{
${ }^{1}$ We thank Pavel Pelikan for further discussions. In a candid email reply of 5 March 2011, he admitted to being 'a little bit nasty' in his response to Hodgson and Knudsen's work. He explained that 'only that for the sake of "selling" Darwinism to economists' he 'felt it necessary clearly to mark my distance from you.' He is concerned that our use of terminology may deter 'virtually all economists'. He describes his friend Hodgson as 'a rich and ramified literature critic and philosophical essayist, whereas' he is 'a simple-minded logical problem-solver, who does not have the patience to continue to read complicated and yet not fully clear texts on a problem, whose solution he can clearly and rapidly see himself.' In response, we think that truth and usefulness are more important than the 'selling' potential of an idea. We also think that Pelikan underestimates his readers when he adopts Dawkins's (contested and controversial) term 'meme' but rejects 'replicator'. Readers will be aware that Dawkins regards the meme as a replicator. Also Pelikan himself uses complicated, unclear and undefined terms such as 'methodological individualism' and 'reductionist'. Despite this, we stress our common ground with Pelikan below.
} 
terminology, to which Pelikan objects (see below). Nevertheless, continuing on the theme of common ground, our emphasis on informational instructions leads us to argue at length that evolution is an informational process at its core.

Like us, Pelikan (2011, p. 357) argues that evolution is a multi-level process involving 'cultural', 'organizational,' and 'national' levels. Our analysis is very similar, but we add some more levels to the picture (Hodgson and Knudsen 2010b, ch. 8). So we have a large measure of agreement.

\section{Rhetorical opposition and some consequences}

Pelikan's largely ungrounded antagonism to our approach operates both at the level of rhetoric and substance. His rhetorical strategy is to attempt to contrast our work 'which stems from the highly abstract spheres of ontology and philosophy of biology' and is 'short of meaningful socioeconomic applications' with his own approach, which is by contrast derived from 'issues of comparative economics, economic reforms, and transformation policies' and hence leads to greater 'applications' (Pelikan 2011, p. 344).

A number of comments are appropriate. First, Pelikan's approach is no less ontological - in the sense of making assumptions about the nature of the world - than ours. A number of pages in his paper are devoted to describing the nature of the evolving system that he proceeds to analyse. This is ontology. Second, his description is no less 'abstract' than ours. There is nothing in principle wrong about being abstract. Abstraction is one of the principal procedures of science.

Third, in Hodgson and Knudsen (2010b) we go to great lengths to give empirical illustrations and applications of our analysis. We are aware that a lot more work is required to create middle-range theory, but we would claim for our work no less capacity for empirical application than the framework devised by Pelikan. That is unsurprising, for they are very similar.

Fourth, the diffusion of Darwinian ideas relating to selection processes has decisively advanced research in many domains of the social sciences, including artificial systems (Holland 1975), evolutionary economics (Nelson and Winter 1982), management science (Levinthal 1997), operations research (Midgley et al. 1997), population ecology (Hannan and Freeman 1989), and organizational behaviour (Nicholson and White 2006). ${ }^{2}$ But without important developments in the philosophy of biology since the 1980s (detailed in our book), the project to generalise Darwinian principles would not have

\footnotetext{
${ }^{2}$ As related in Hodgson and Knudsen (2010b), the explanatory and descriptive power of Darwinism turns on the way the theory can account for selection processes in nature and society. The list of contributions that draw on Darwinian ideas to analyse selection processes can easily be expanded.
} 
progressed, and a common set of theoretical standards and reference points would have been missing.

It is a shame that Pelikan generally regards classical inspirations for evolutionary approaches as well as recent developments in the philosophy of biology as too 'abstract'. Yet he turns to abstract, philosophically-laden terminology when it suits, to proclaim 'methodological individualism' and 'reductionist' views (Pelikan 2011, p. 345). Yet he defines neither term. Both terms are ambiguous and the first is particularly contentious, having several different meanings (Hodgson 2007). Which of the many versions of these terms does Pelikan advocate?

Fifth, he places his (undefined) 'methodological individualism' and 'reductionist' views as contrasting with our own work. Pelikan (2011, p. 344) writes of his own work:

the present generalization of Darwinism will be given the form of a conceptual agent-based model. This will provide it with a solid microbasis and establish a well-defined link to methodological individualism in the social sciences.

He then remarks that Hodgson-Knudsen generalised Darwinism 'has no clear micro-basis' and this 'appears to be another reason ... why it is so short of meaningful socioeconomic applications.' (p. 4)

We hardly think that he could be writing about us. Like Pelikan we use agent-based models (Hodgson and Knudsen 2004a, 2006b, 2008b, 2010a, b) in an evolutionary context. As for 'no clear micro-basis', we make extensive reference to individuals, individual motivations and individual psychology. Indeed we would claim that there is far more reference to psychology in our work than in Pelikan (2011).

Sixth, his apparent dismissal of the philosophy of biology weakens some of his own formulations. Pelikan (2011, p. 351) says he agrees with 'Dawkins's (1976) argument that in Darwinian evolution the units of selection are genes and not organisms.' This is written in apparent ignorance of the forensic criticism by philosophers of biology of Dawkins's formulation. For example. David Hull (2001, p. 61) argued: 'When Dawkins says that genes are the units of selection, he means replication.' Confusion over Dawkins's formulation led Elliott Sober (1984) to make a useful distinction between 'selection of' and 'selection for.' Within the replicator-interactor framework we modify Sober's usage, to write of selection of interactors leading to selection for replicators. ${ }^{3}$ For example, the selection of zebras (due to predators, diseases and other adversities) leads to changes in the zebra population and their gene pool, involving the selection for specific genes that may bestow fitness advantages in particular contexts.

\footnotetext{
${ }^{3}$ We thank Jack Vromen for pointing out the difference between our's and Sober's use of the selection of/for terminology.
} 
Whatever terminology we use, simply saying 'units of selection' is too blunt and imprecise. Used by many others, this phrase has led to much confusion, and this has been both exposed and repaired by philosophers. We urge people working in this area - including evolutionary economists - to take these philosophical contributions seriously.

\section{Pelikan's apparent dismissal of the concept of replication}

Pelikan (2011, pp. 343 n., 4) writes: 'The emphasis on replicating is an important reason why HKGD [Hodgson-Knudsen generalised Darwinism] is of so little use in the social sciences' and of our 'misplaced focus on replicating'.

What do we mean by replication? Hodgson and Knudsen (2010b, pp. ix, 112) contains the following statements on replication: 'We regard the storing and replication of information as central to social evolution ... Generally replication involves the transmission of information that may create or modify a replicator'. We regard a replicator as consisting of program-like bits of information, held by an entity (interactor), that can represent adaptive solutions to problems and guide its development. We also provide a technical definition of replication in the text and glossary. We treat replication and inheritance as synonyms.

Given that we share with Pelikan the emphasis on the role of informational instructions in evolution, it is difficult to see how we can manage without the replicator concept. If there is no replication then there is no way in which these instructions can be passed from one entity to another. The information would simply die out when it lost its individual or organisational supports. Replication seems essential.

It is. Pelikan (2011, p. 351) writes: 'In socioeconomic evolution, new instructions spread both laterally, among the actually present individuals, and from one generation to the next.' He also mentions rules that are 'widely imitated' (p. 357). Pelikan (2011, pp. 361-362) approvingly quotes Dawkins on memes as 'units of cultural ideas, symbols or practices, which can be transmitted from one mind to another' and writes himself about 'imports of economically detrimental memes'.

Bluntly, all these statements of the 'spread' of instructions, 'imitated' rules, 'transmitted' memes and 'imports' of memes, are conceptually equivalent to replication. We have strong reservations about the meme concept (Hodgson and Knudsen 2010b, pp. 132-6) but that is a different matter. Dawkins regard memes as replicators and Pelikan has embraced them. Pelikan has a concept of replication, described in different terms.

As for the claim that our adoption of replication being 'of so little use in the social sciences', we give example after example of replication in social and business contexts. Our examples include the rather special case of spinoffs, where firms create offspring (Hodgson and Knudsen 2010b, p. 175). Also, according to our definitions, the diffusion of business routines is an example of 
replication. Again we give several concrete examples (Hodgson and Knudsen 2010b, p. 143).

Not only does Pelikan implicitly have replicators, he also has interactors. His distinction between 'b-agents' and ' $\mathrm{C}$-agents' is close to the replicatorinteractor distinction. ${ }^{4}$ This is of relevance to the question of Lamarckism, to which we now turn.

\section{The Lamarckian claim}

On the thorny question of Lamarckism. Pelikan (2011, p. 351) writes:

Following Nelson and Winter (1982) - with the notable, but for me difficult to understand exception of Hodgson and Knudsen (2006a) most of evolutionary economists appear to agree that in this sense, socioeconomic evolution is indeed partly Lamarckian.

This is a misunderstanding of our position. In our work we admit the possibility of processes where the acquired characters of an interactor (social phenotype) can affect its replicators (social genotypes). But we contend that it is misleading to describe this as Lamarckian. Why? There are several steps to the argument - see below. But since Pelikan agrees with us that social evolution is essentially a Darwinian process, we do not have to repeat the additional arguments here that

(a) Lamarckism and Darwinism are not rivals, and

(b) if social evolution were Lamarckian then it also would have to be Darwinian (Aldrich et al. 2008; Hodgson and Knudsen 2006a, 2010b).

Instead we can focus here on why the 'Lamarckian' label is misleading in the social context.

\section{Unpacking Lamarckism}

Step 1. What is Lamarckism?

In Hodgson and Knudsen (2006a, 2010b) we consider various positions held by Lamarck and Lamarckians. We argue that it is reasonable to define Lamarckism as the inheritance of acquired characters. At least that is the meaning that we concentrate on.

\footnotetext{
${ }^{4}$ Essentially, Pelikan's (2011) b-agents replicate instructions that, in part, influence the development of more complex entities, the C-agents. This basic explanatory structure can be used to account for selection processes in larger systems that span multiple levels of analysis. Hodgson and Knudsen (2004b, 2010b) show how this can be done using the replicator-interactor framework.
} 
Step 2. Defining Lamarckism requires something like the genotypephenotype distinction

One dog catches fleas and passes some of them to another dog. Is that Lamarckian inheritance? If so, the fleas must be regarded as an acquired character and their jumping from one animal to another must be treated as inheritance. Similar arguments must apply to a host of other phenomena such as catching a cold and contagious laughter. All those processes would qualify on similar grounds as Lamarckian.

But almost all biologists now deny that acquired characters can be inherited in the biological sphere and reject Lamarckism. None of them would see the phenomena described in the previous paragraph as a challenge to the current consensus in biology. We are not saying that what is true in biology must be also true in social evolution. Our point is different.

As David Hull (1982) points out, more must be added to make the Lamarckian claim meaningful. Inheritance must be distinguished from infection or contagion. The extra ingredient must be the genotype-phenotype distinction or a relevant equivalent. It is only with such a distinction that inheritance can be properly defined and distinguished from catching colds or fleas.

The genotype-phenotype distinction was introduced in biology in the twentieth century, long after the deaths of Lamarck and Darwin. But it is necessary to understand this issue. Any infection or contagion immediately affects the phenotype, not the genotype. By contrast, the Lamarckian inheritance of acquired characters means that a development in a phenotype can affect its own genotype, by some presumed internal process. We know in biology that this does not happen, but that is not the point. We need to establish the difference in principle between Lamarckian inheritance and contagion.

More generally, the genotype-phenotype distinction is a conceptual advance that helps develop the evolutionary program in economics. In early versions of Nelson and Winter's (1982) evolutionary theory, routines both served a duty of carrying inheritable instructions (genotypes) and being the actual expression of these instructions (phenotype). After it has become clear that the role of routines is to pass on inheritable instructions (i.e. to function as replicators), we can now focus on how these instructions trigger developmental processes and thereby become expressed in particular entities. This is important because it allows social scientists to study the learning processes that are situated within a broader selection environment (e.g. learning in firms that are subject to exit and entry processes).

Several authors suggest the term replicator as a generalisation of genotype, and interactor as a generalisation of phenotype (Hull 1988; Brandon 1996). As generalisations they apply to social as well as biological evolution. We have described replicators above. Following Hull (1988) we define an interactor as a relatively cohesive entity that hosts replicators and interacts with its environment in such a way as to lead to changes in the population of interactors and their replicators. We also give a more precise definition. 
Step 3. Identifying the social replicators (genotypes) and social interactors (phenotypes)

In order to consider and understand the possibility of Lamarckian inheritance we must first identify the replicators and interactors in the social domain. We must then consider the possibility that the acquired character of an interactor can affect its replicators.

As Hull (1982) points out, the passing of memes (as replicators) from person to person would not be the inheritance of acquired characters because the ideas themselves have been defined as replicators and not characteristics. One of the problems with the meme concept is that it is unclear whether it is a replicator or an interactor.

The pragmatist approach of Charles Sanders Peirce, William James, John Dewey and Thorstein Veblen helps here. Pragmatism sees ideas as grounded on habits, which in turn are learned dispositions to behave in a particular way in particular circumstances.

Habits are hosted by individuals as their interactors. Further examples of social replicators include routines, by which we refer to dispositions within organisations to carry out sequences of actions. Routines are hosted by organisations as their interactors, and in turn are built on the habits of the individuals involved.

Step 4. Is Lamarckian social inheritance possible? And meaningful?

Ideas are either replicators or (features of) interactors. If they are features of interactors then the spreading of ideas from one interactor to another is an example of contagion, not Lamarckism. If ideas are replicators, then (as pointed out above) their diffusion is the copying of replicators rather than acquired characters. This again is not Lamarckism.

Consider the replication (copying) of habits. Someone teaches us a new language. We imitate and repeat. We are corrected. This goes on until our responses are ingrained in habit. Gradually the knowledge of the language is transferred from one person to another. The replicators are replicated.

But note that the process of habit replication relies on behavioural imitation. (The way in which habits of thought are copied is more complex; it relies on language and is discussed in Hodgson and Knudsen 2010b, pp. 138-9.) In all cases of habit replication, the mechanism of replication goes through the interactor. Unlike genes in biology, there is no direct copying from replicator to replicator.

At first sight this seems very Lamarckian, because as we repeat the behaviour of our teacher we develop the appropriate habits, our acquired behaviour (copied from another) gets encoded in our own habits. Our habit replicators change because we acquire a behavioural characteristic. We have freely admitted that this Lamarckian link (from our behaviour to our habit) does exist (Hodgson and Knudsen 2006a, 2010b).

But the indirectness of habit replication creates problems for the Lamarckian story. The Lamarckian link (from our behaviour to our habit) is a 
causal cul-de-sac. All it does is ensure that we retain the capacity to repeat the behaviour. The Lamarckian link plays no part itself in the inheritance process. This is very different from any imagined Lamarckian process in the biological sphere, where replicators get copied directly. That is another reason why the Lamarckian description in the social sphere is misleading rather than strictly wrong. Ironically, the Lamarckian concept is more appropriate for the biological sphere, despite its invalidity in that domain.

Similar arguments apply to the replication of organisational routines, because that process too is grounded on the replication of individual habits (see Hodgson and Knudsen 2006a, 2010b).

\section{Why Lamarckian inheritance may be limited}

There are additional arguments why Lamarckian inheritance, if it existed, would be limited. The introduction of too much Lamarckian influence would mean that much cognitive and extraneous noise would interfere with the tried and tested information in the replicators. In Hodgson and Knudsen (2008a, $2010 \mathrm{a}, \mathrm{b})$ we show that the generation of complexity in an evolving system depends critically on the minimisation of copy error. Too much Lamarckian meddling with genotypes and replicators would mean too much response to the accidental and superficial, rather than the enduring properties of the environment. Crucial information would be lost and the growth of complex outcomes would be more difficult.

There is also the fact that Lamarckism remains fairly unimportant in economics. A JSTOR search, conducted 7 March 2011, revealed that its 121 economics journals contained a total of 66 articles that either used the terms 'Lamarckism' or 'Lamarckian' (anywhere) in the text while 1,522 articles either used the terms 'Darwinism' or 'Darwinian'.

The claim by some social scientists that social evolution is Lamarckian is a distraction from the compelling conclusion that it is Darwinian, and that Darwinian ideas can be helpful in understanding the processes. Lamarckism does not provide an adequate evolutionary framework and it is a red herring.

\section{Conclusion}

We must turn to a generalised Darwinism and build the required middle-range theory to show its relevance and utility. Claiming more disagreement than really exists is a diversion from this shared endeavour. Instead, we should aim to add further material to the common building of evolutionary theory in the social sciences.

\footnotetext{
${ }^{5}$ The JSTOR search included all available years from 1886 to 2011.
} 


\section{References}

Aldrich HE, Hodgson GM, Hull DL, Knudsen T, Mokyr J, Vanberg VJ (2008) In defence of generalized Darwinism. J Evol Econ 18(5):577-596

Brandon RN (1996) Concepts and methods in evolutionary biology. Cambridge University Press, Cambridge and New York

Dawkins R (1976) The selfish gene. Oxford University Press, Oxford

Hannan MT, Freeman J (1989) Organisational ecology. Harvard University Press, Cambridge, MA

Hodgson GM (1993) Economics and evolution: bringing life back into economics. Polity Press and University of Michigan Press, Cambridge, UK and Ann Arbor, MI

Hodgson GM (2007) Meanings of methodological individualism. J Econ Methodol 14(2):211-226

Hodgson GM, Knudsen T (2004a) The complex evolution of a simple traffic convention: the functions and implications of habit. J Econ Behav Organ 54(1):19-47

Hodgson GM, Knudsen T (2004b) The firm as an interactor: firms as vehicles for habits and routines. J Evol Econ 14(3):281-307

Hodgson GM, Knudsen T (2006a) Dismantling Lamarckism: why descriptions of socio-economic evolution as Lamarckian are misleading. J Evol Econ 16(4):343-366

Hodgson GM, Knudsen T (2006b) Balancing inertia, innovation, and imitation in complex environments. J Econ Issues 40(2):287-295

Hodgson GM, Knudsen T (2008a) Information, complexity and generative replication. Biol Philos 43(1):47-65

Hodgson GM, Knudsen T (2008b) The emergence of property rights enforcement in early trade: a behavioral model without reputational effects. J Econ Behav Organ 68:48-62

Hodgson GM, Knudsen T (2010a) Generative replication and the evolution of complexity. J Econ Behav Organ 75(1):12-24

Hodgson GM, Knudsen T (2010b) Darwin's conjecture: the search for general principles of social and economic evolution. University of Chicago Press, Chicago

Holland J (1975) Adaptation in natural and artificial systems. University of Michigan Press, Ann Arbor, MI

Hull DL (1982) The naked Meme. In: Plotkin HC (ed) (1982) Learning, development and culture: essays in evolutionary epistemology. Wiley, New York, pp 273-327

Hull DL (1988) Science as a process: an evolutionary account of the social and conceptual development of science. University of Chicago Press, Chicago

Hull DL (2001) Science and selection. Essays on biological evolution and the philosophy of science. Cambridge University Press, Cambridge

Levinthal DA (1997) Adaptation on rugged landscapes. Manag Sci 43(7):934-950

Midgley DF, Marks RE, Cooper LG (1997) Breeding competitive strategies. Manag Sci 43(3):257275

Nelson RR, Winter SG (1982) An evolutionary theory of economic change. Belknap Press, Cambridge, MA

Nicholson N, White R (2006) Darwinism—a new paradigm for organizational behavior? J Organ Behav 27:111-119

Pelikan P (2011) Evolutionary developmental economics: how to generalize Darwinism fruitfully to help comprehend economic change. J Evol Econ 21:341-366

Sober E (1984) The nature of selection: evolutionary theory in philosophical focus. MIT Press, Cambridge, MA 